\title{
Model predictive control and estimation of managed pressure drilling using a real-time high fidelity flow model
}

Junho Park

Brigham Young University

Cameron Price

Brigham Young University

David Pixton

Brigham Young University

Manuel Aghito

SINTEF

Roar Nybø

SINTEF

Follow this and additional works at: https://scholarsarchive.byu.edu/facpub See next page for additional authors

Part of the Chemical Engineering Commons

\section{Original Publication Citation}

https://www.sciencedirect.com/science/article/abs/pii/S0019057820302238

\section{BYU ScholarsArchive Citation}

Park, Junho; Price, Cameron; Pixton, David; Aghito, Manuel; Nybø, Roar; Bjørkevoll, Knut; and Hedengren, John, "Model predictive control and estimation of managed pressure drilling using a real-time high fidelity flow model" (2020). Faculty Publications. 4167.

https://scholarsarchive.byu.edu/facpub/4167

This Peer-Reviewed Article is brought to you for free and open access by BYU ScholarsArchive. It has been accepted for inclusion in Faculty Publications by an authorized administrator of BYU ScholarsArchive. For more information, please contact ellen_amatangelo@byu.edu. 


\section{Authors}

Junho Park, Cameron Price, David Pixton, Manuel Aghito, Roar Nybø, Knut Bjørkevoll, and John Hedengren 


\title{
Model Predictive Control and Estimation of Managed Pressure Drilling using a Real-Time High Fidelity Flow Model
}

\author{
Junho Park ${ }^{\mathrm{a}}$, Cameron Price ${ }^{\mathrm{a}}$, David Pixton ${ }^{\mathrm{a}}$, Manuel Aghito $^{\mathrm{b}}$, Roar Nyb $\varnothing^{\mathrm{b}}$, \\ Knut Bjørkevoll ${ }^{\mathrm{b}}$, John D. Hedengren ${ }^{\mathrm{a}, *}$ \\ ${ }^{a}$ Department of Chemical Engineering, Brigham Young University, Provo, Utah, USA \\ ${ }^{b}$ SINTEF, Trondheim, Norway
}

\begin{abstract}
When drilling an oil or gas well, well pressures may be controlled using a technology called managed pressure drilling. This technology often relies on model predictive control schemes; however, practical limitations have generally led to the use of simplified controller models that do not optimally handle certain perturbations in the physical system. The present work reports on the first implementation of a highly accurate system model that has been adapted for real-time use in a controller. This real-time high-fidelity model approximates the results of offline high-fidelity models without requiring operation by model experts. The effectiveness of the model is demonstrated through simulation studies of controller behavior under various drilling conditions, including an evaluation of the impact of sparse downhole feedback measurements.

Keywords: managed pressure drilling, drilling automation, pressure control, physics-based drilling flow model, nonlinear model predictive control
\end{abstract}

\section{Introduction}

2 Control of well pressures during oil and gas drilling operations is a safety3 critical process. If the pressure of drilling fluid in the well is allowed to get too

\footnotetext{
${ }^{*}$ corresponding author

Email address: john_hedengren@byu.edu (John D. Hedengren)
} 
4 low, fluids residing in the surrounding rock formation can enter the wellbore dur-

5 ing the drilling process, creating a potentially hazardous condition. Likewise, if the drilling fluid pressure is too high, the formation wall may fracture, causing costly fluid loss to the surrounding rock and perhaps creating a secondary incursion of formation fluid into the wellbore. Some wells in offshore environments or depleted reservoirs are particularly difficult to drill from this perspective, as the margin between formation fluid pressure (pore pressure) and fracture pressure can be quite narrow. Sometimes, pressure fluctuations caused simply by rapid movement of drilling components in and out of the well is sufficient to exceed safety limits.

One technology that offers highly responsive control over wellbore pressures during the drilling process is managed pressure drilling (MPD). This technology uses dynamically adjusted surface equipment, including a choke valve and multiple fluid pumps, to keep pressures within desired limits. Though a variety of controllers have been used to control MPD equipment $[1,2,3,4]$, model predictive control (MPC) is particularly well suited to this application.

MPC has found favor in a variety of industries for several reasons, including its capability of handling multiple inputs and outputs, and its ability to handle input and state constraints $[5,6,7]$. In MPD applications, researchers have exploited these capabilities and have developed MPC systems that control pressure, flow, and rate of penetration (ROP) simultaneously [8, 9], control pressure at two different locations in the well [10], and handle substantial heave motion on drill rigs subject to ocean surface disturbances $[11,12]$.

Understandably, a fundamental key to controller effectiveness is the accuracy of the model upon which the MPC is based; mismatches between the model and the physical system can lead to suboptimal control. Nevertheless, a simplified model is often accepted for use in the MPC in order to address practical limitations relating to such things as incomplete understanding of the physical process, limited computational power, or inadequate availability of expertise for control system maintenance, often trading optimal process control for usability [13]. Indeed, in many MPC applications, models include simplifications of some type, 
such as reduction in model order or linearization of significant nonlinear processes (see $[9,10,14,15,16,17,18,19])$. The simplest of these models may be termed gray box models, which incorporate linear transfer function models and nonlinearity blocks to describe relationships between manipulated variables and system behavior. These models have been derived empirically and may take the form of a nonlinear Hammerstein-Wiener model, for example [20, 21, 22, 23]. To improve this type of model, Patan [24] proposes using artificial neural networks to empirically build system models off-line. Other models ("low-fidelity flow models" or LFMs) are based on the underlying physics of the process, and capture the primary dynamics of the process [25], but exclude more complex but nonetheless relevant physical effects in the name of simplification.

Because such models necessarily omit certain physical effects, the compromised accuracy of these reduced order models is inevitable; studies suggest improved results could be achieved with more accurate models [8, 12]. Model errors due to structural model mismatch become more prominent during transient periods caused by operational changes. For example, Pedersen, et.al. [26], note the criticality of improved models when controlling pressures in the well during large process changes. During such changes a physical process will often pass through multiple nonlinear modes that are not well tracked by simpler models, e.g., passing through different flow regimes.

Another approach to addressing practical computing issues includes segregating optimization activities into off-line and on-line portions where optimal control solutions for various states are pre-computed and made available to simplified on-line routines [27, 28]. Such approaches deal effectively with limited computing facility but still inevitably detach the run-time model from some important aspects of the underlying physics of the process. In the oil and gas drilling industry, process variations due to geologic idiosyncrasies, previous production of a reservoir, etc. abound, suggesting substantial benefits can be secured with control systems integrated with reliable physics-based models [29].

Highly accurate physics-based models of the well drilling dynamic processes do exist. Such models are typically very detailed in order to capture complex 


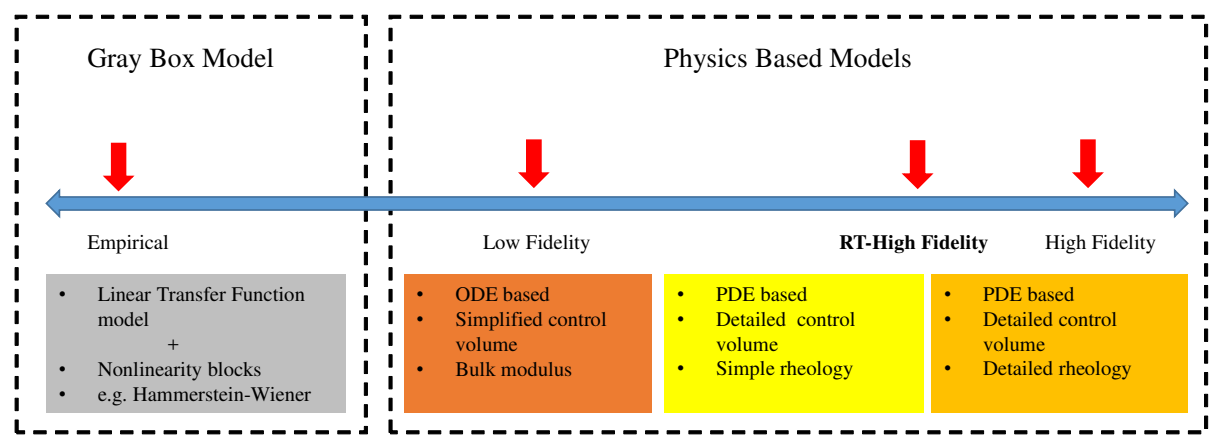

Figure 1: Spectrum of model fidelity in MPD automation 
In the sections following, this RT-HFM model is described in detail, in context with LFM and HFM models. Its implementation into a MPC with a MHE (moving horizon estimator) is then detailed. Finally, results of testing this new control system are presented. This testing simulates an array of conditions encountered while drilling oil and gas wells, including "normal" drilling ahead, making a pipe connection to change the length of the drill string, and displacing drilling fluid of one density with that of another density. The effectiveness of control based on the RT-HFM is further demonstrated by considering both the case where down-hole sensor data is available to provide BHP feedback to the model, and the case where sensor feedback is interrupted or severely limited. This latter case is meaningful in the oil and gas environment due to the extreme conditions encountered and the wide diversity of drilling operations, both of which impact the quality or availability of sensor data.

\section{Real-Time High Fidelity Flow Model}

This section provides an overview of the RT-HFM and how it compares to other models used for control system development. First, a schematic and description of MPD gives context for the dynamic relationships that are modeled to create a predictive controller. Next, a description is given of three models of differing complexity, including the RT-HFM. The RT-HFM model is presented to contrast the obstacles facing both low and high fidelity models.

\subsection{Basic Flow Circuit and Related Parameters}

To construct an oil or gas well, a drill bit is attached to a long assembly of tubular components (drill string) that provide thrust and rotation to the bit. As it penetrates the rock formation, the drill bit creates a hole that is larger than the diameter of the drill string, thereby providing an annular space between the formation and the drill string. Drilling fluid occupies this annulus and also the inside of the drill string, and serves to maintain a pressure against the formation that controls the flow of fluids out of the formation. When actively 
drilling, mud pumps located at the surface circulate the drilling fluid through the drill string to the bottom of the well, where the fluid entrains cuttings and carries them back to the surface through the annulus. In modeling this system, the cross sectional areas of the annulus and the drill string bore, the flow rate of the drilling fluid, and certain physical properties of the drilling fluid, entrained cuttings, and entrained formation fluids are important parameters.

An MPD system additionally contains a choke valve and an auxiliary charge pump, both located at the top of the well on the annulus side of the flow circuit. By manipulating the flow rate of the mud pumps and the opening of the choke valve, the backpressure in the fluid may be regulated, which provides for fine control of the BHP while drilling fluid is flowing. When mud pumps are not generating sufficient backpressure, e.g., when the fluid is not flowing, the auxiliary charge pump may be employed to increase annulus pressure. Figure 2 shows a simplified schematic of a typical MPD system. In the present study, pressure is managed by manipulating back pressure alone. Though other techniques such as manipulation of annular fluid level, mud density, etc can be part of an MPD system, they are not studied in this paper. The MPC manipulates two variables, the mud pump flow and the choke pressure. We assume cascading control of back pressure pump flow and the choke valve opening based on the choke pressure. 


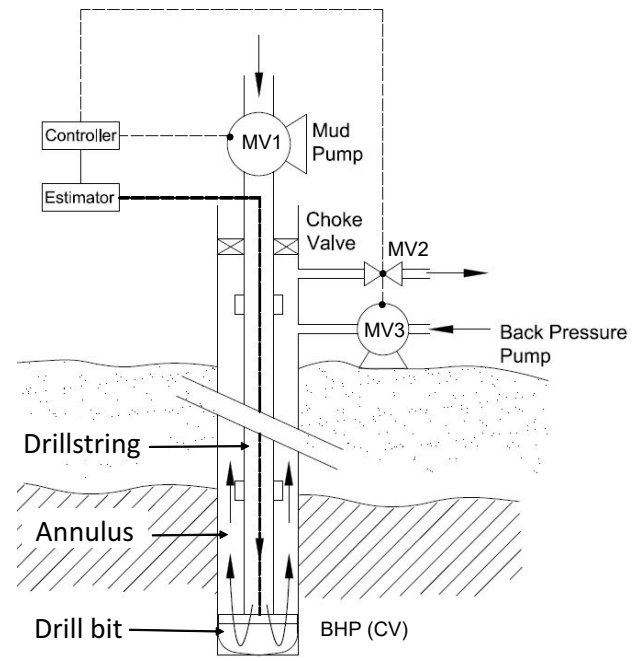

Figure 2: MPD Schematic

The low-fidelity flow model (LFM) developed by Kaasa et al. [25] simplifies the drilling operation into two control volumes and introduces the two physical parameters bulk modulus $(\beta)$ and effective mud density $(M)$. References $[9$, $14,15,16,17,18]$ are the MPC applications employing the LFM. The LFM equations and variable descriptions are shown in Equations 1 to 4 and Table 1.

$$
\begin{aligned}
& \dot{p}_{p}=\frac{\beta_{d}}{V_{d}}\left(q_{p}-q_{b i t}\right) \\
& \dot{p}_{c}=\frac{\beta_{a}}{V_{a}}\left(q_{b i t}+q_{b a c k}-q_{c}+q_{r e s}\right) \\
& \dot{q}_{b i t}=\frac{1}{M}\left(p_{p}-f_{d} q_{b i t}^{2}+\rho_{d} g_{c} h_{b i t}-p_{b i t}\right) \\
& p_{b i t}=p_{c}+\rho_{a} f_{a} h_{b i t} q_{b i t}^{2}+\rho_{a} g_{c} h_{b i t}
\end{aligned}
$$


Table 1: Summary of parameters used in LFM

\begin{tabular}{cll}
\hline Parameter & Description & Unit \\
\hline$p_{p}, p_{c}, p_{b i t}$ & Pressure at mud pump, choke valve, and bottomhole & bar \\
$q_{p}, q_{c}, q_{b i t}$ & Volumetric flow rate at mud pump, choke valve, & \\
& and bottomhole & $\mathrm{m}^{3} / \mathrm{min}$ \\
$q_{r e s}$ & Volumetric flow rate of reservoir gas influx & $\mathrm{m}^{3} / \mathrm{min}$ \\
$\beta_{a}, \beta_{d}$ & Bulk modulus of the fluid in annulus and drill string & $\mathrm{bar}$ \\
$M$ & Effective density per unit length & $\mathrm{kgm}^{-4} 10 \mathrm{e}^{-5}$ \\
$f_{a}, f_{d}$ & Friction coefficients of annulus and drill string & $\mathrm{s}^{2} \mathrm{~m}^{-6}$ \\
$V_{a}, V_{d}$ & Volumes of annulus and drill string & $\mathrm{m}^{3}$ \\
$h_{b i t}$ & Well depth & $\mathrm{m}$ \\
\hline
\end{tabular}

\subsection{High Fidelity Flow Model Equations}

The high fidelity flow model (HFM) was developed before the LFM, and has been used extensively for improving understanding of drilling operation hydraulics, to both assist the well design process and to provide real-time advisory assistance for many field applications [31]. However, the HFM equations are much more comprehensive than other models and therefore the model must be configured, monitored and tuned by an expert. Even then, model simulations that are free from numerical instability cannot be fully assured [32]. Due to these factors, such models are not being employed for real-time drilling automation applications, including MPC, which requires fast calculation speed and computational robustness. The governing equations of HFM are presented in [29] and are shown in Equations 5 to 12 and Table 2.

$$
\begin{aligned}
& \frac{\partial}{\partial t}\left(A \alpha_{m} \rho_{m}\right)=-\frac{\partial}{\partial s}\left(A \alpha_{m} v_{m} \rho_{m}\right)+A \dot{m}_{g, m} \\
& \frac{\partial}{\partial t}\left(A \alpha_{g} \rho_{g}\right)=-\frac{\partial}{\partial s}\left(A \alpha_{g} v_{g} \rho_{g}\right)-A \dot{m}_{g}+q_{f g} \\
& \frac{\partial}{\partial t}\left(A \alpha_{m} x_{d g, m} \rho_{m}\right)=-\frac{\partial}{\partial s}\left(A \alpha_{m} v_{m} x_{d g, m} \rho_{m}\right)-A \dot{m}_{g, m} \\
& \frac{\partial}{\partial t}\left(A \alpha_{f o} \rho_{f o}\right)=-\frac{\partial}{\partial s}\left(A \alpha_{f o} v_{f o} \rho_{f o}\right)+A \dot{m}_{g, f o}+q_{d g}+q_{f o}
\end{aligned}
$$




$$
\begin{aligned}
& \frac{\partial}{\partial t}\left(A \alpha_{f o} x_{d g, f o} \rho_{f o}\right)=-\frac{\partial}{\partial s}\left(A \alpha_{f o} v_{f o} x_{d g, f o} \rho_{f o}\right)+A \dot{m}_{g, f o}+q_{d g} \\
& \frac{\partial}{\partial t}\left(A \alpha_{f w} \rho_{f w}\right)=-\frac{\partial}{\partial s}\left(A \alpha_{f w} v_{f w} \rho_{f w}\right)+q_{f w} \\
& \frac{\partial}{\partial t}\left(A \alpha_{c} \rho_{c}\right)=-\frac{\partial}{\partial s}\left(A \alpha_{c} v_{c} \rho_{c}\right)+q_{c} \\
& \frac{\partial}{\partial t}\left[A\left(\alpha_{m} \rho_{m} v_{m}^{2}+\alpha_{g} \rho_{g} v_{g}^{2}+\alpha_{f o} \rho_{f o} v_{f o}^{2}+\alpha_{f w} \rho_{f w} v_{f w}^{2}+\alpha_{c} \rho_{c} v_{c}^{c}\right]\right. \\
& +\frac{\partial}{\partial s}\left[A\left(\alpha_{m} \rho_{m} v_{m}^{2}+\alpha_{g} \rho_{g} v_{g}^{2}+\alpha_{f o} \rho_{f o} v_{f o}^{2}+\alpha_{f w} \rho_{f w} v_{f w}^{2}+\alpha_{c} \rho_{c} v_{c}^{c}\right]\right. \\
& =-\frac{\partial(A p)}{\partial s}-A\left(\frac{\partial p}{\partial s}\right)_{f r i c} \\
& \quad+A\left[\alpha_{m} \rho m+\alpha_{g} \rho g+\alpha_{f o} \rho f o+\alpha_{f w} \rho f w+\alpha_{c} \rho c\right] g \cos \theta
\end{aligned}
$$

Table 2: Summary of parameters used in HFM

\begin{tabular}{clc}
\hline Parameter & Description & Unit \\
\hline$A$ & Flow line cross sectional area & $\mathrm{m}^{2}$ \\
$\alpha_{a}$ & Volume fraction of $a$ & $\mathrm{~m}^{3}$ \\
$v_{a}$ & Volume of $a$ & $\mathrm{~m}^{3} / \mathrm{s}$ \\
$q_{a}$ & Volumetric flow rate of $a$ & $\mathrm{kgm}^{-3}$ \\
$\rho_{a}$ & Density of $a$ & \\
$x_{a, b}$ & Mass fraction of $a$ in $b$ & $\mathrm{bar}$ \\
$f r i c$ & Frictional pressure loss & \\
$m, g, f o, f w, c$ & Drilling mud, gas, formation oil, formation water, & \\
$\dot{m}_{g, n}, \dot{m}_{g, f o}$ & Rates of gas dissolution in drilling mud and formation oil & $\mathrm{kg} / \mathrm{s}$ \\
\hline
\end{tabular}

\subsection{Modifications of HFM for Real-time Use}

Recently, work on a RT-HFM was announced, as part of an effort to decrease the computational cost of the HFM while still maintaining high model accuracy [32]. Since that time, a working model has been developed, and initial application testing has been completed as will be described below. The calculations in both the RT-HFM and HFM are based on a discretization of the well volume, and employ a numerical solver for the mass and momentum conservation equations (Equations 5 to 12) that govern the physics of the well. Mass transport 
is calculated using the finite difference method on a one-dimensional grid, with analytical solutions used to account for radial dependencies.

Like the HFM, the RT-HFM is a dynamic model that accurately simulates significant fluid characteristics. For example, mass transport calculations in the RT-HFM respect conservation of mass per component of the fluid, and respect conservation of total momentum locally. Thus, the model accurately represents dynamic effects such as compression of the fluid propagating along the well. To reduce numerical iterations and the chance of model instability, the accuracy of the model during the transient phases is relaxed.

Calculation complexity is also reduced in the RT-HFM by keeping the temperature profile fixed, as has already been described in the previous paper [32]. Fluid property sub-models are also simplified to enable rapid and stable computation. For example, in the sub-model that describes rheological behavior, the HFM fits rheological property data to a non-linear Herschel Bulkley model, while the RT-HFM utilizes the linear Bingham Plastic model, expressed as $\tau=$ $\tau_{0}+\mu_{\infty} \gamma$, where $\tau$ is the shear stress and $\gamma$ is the shear rate. In this Bingham model, the rheological properties of the fluid are determined by the yield stress $\tau_{0}$ and the plastic viscosity $\mu_{\infty}$. The model calculates plastic viscosity and yield stress using a best fit to all available rheological data which means that calculations normally match much better at low RPM values than the standard procedure that uses only 300 and 600 RPM readings to find plastic viscosity and yield stress. Compared to Herschel-Bulkley, the Bingham equation has an accurate explicit solution for laminar flow, and the calculation is faster and more robust for estimating the frictional pressure loss. Still, calculations in the RTHFM are relatively sophisticated, and include, among other features, pressureand temperature-dependent fluid properties, with density either from published correlations or from input tables of laboratory data. Rheological behavior data can be given in tabular form for different combinations of pressure and temperature, in which case interpolation is used to get rheological behavior parameters at the actual temperature in each grid box.

The RT-HFM is therefore much faster and robust than the HFM, and at the 
same time more accurate than existing lower order models. Geometrical changes in the drill string and wellbore, e.g., a tapered drill string, are accommodated by the model. However, some other specific conditions are not accounted in the RT-HFM, e.g., a mud flow diversion through an underreamer, and pressure loss through a mud motor. Although the frictional pressure loss by the drill string rotation is included in the RT-HFM, the drill string vibration effects on the BHP and heave motion of the offshore rig are not considered in this study. However, such effects can be simulated in the model by inputting bit depth changes, thereby allowing calculation of pressure surge and swab effects. The difference in steady-state BHP output from the two models, as determined by simulations using various combinations of input variables, is shown in Figure 3. As shown, at the upper limits of flow and choke pressure considered in the present study, the difference in pressure prediction amounts to less than 2.5 bar. At the point of primary interest in these simulations, which is in an $8-1 / 2$ inch section (see Table 8), this difference appears to be reasonable for effective model-based control.

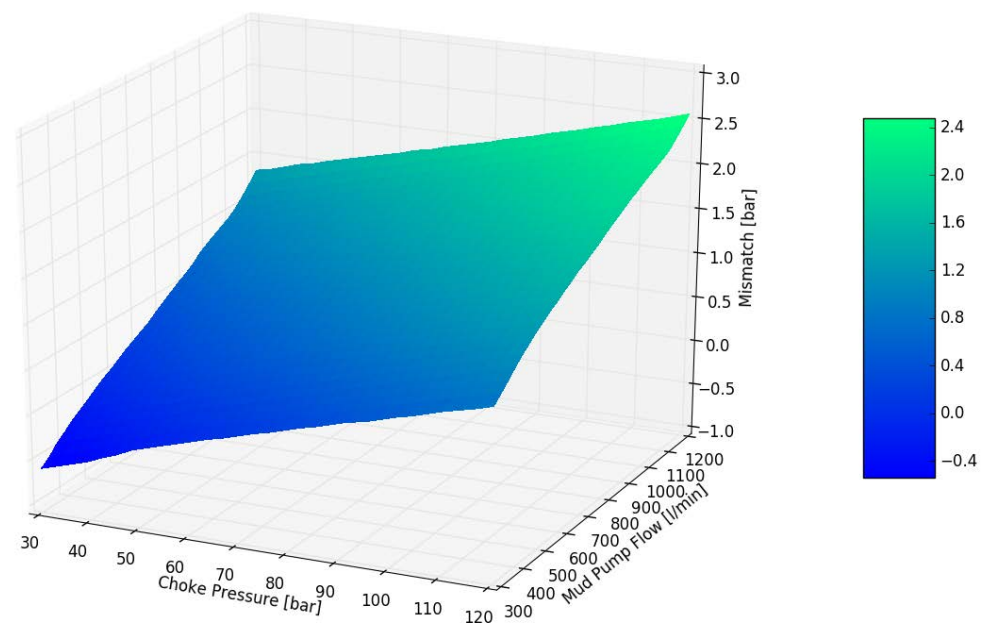

Figure 3: Difference between steady state BHP output from HFM and RT-HFM to identify model mismatch at varying conditions 


\section{System Configurations}

Control system architecture for MPD automation varies according to the availability of BHP data. Two potential architectures are portrayed in Figures 4 and 5, including a semi-closed loop configuration and a full-closed loop configuration. These figures display block diagrams of the signal chains for each architecture, where blocks labeled MPC represent a controller, MHE labeled blocks represent an estimator, and system models (HFM, RT-HFM) are shown in each appropriate block. Dashed lines represent the input signals of the controller that are computed from hydraulic models as opposed to solid lines represent the measured value from the rig. If BHP measurements are available, a solid line between the rig and the controller and/or estimator represents the path of measured data. Note that in these figures, the rig represents the equipment involved in the drilling process, most specifically including mud pumps, a choke valve, a charge pump feeding into the wells annulus, and automatic controls for each of these pieces of equipment.

Figure 4 represents a semi-closed loop configuration, which is a common configuration in MPD automation research when downhole data is sparse or unavailable. To provide this missing feedback data, a MHE is introduced in this configuration as a "soft" sensor to estimate the BHP from surface measurements. While MHE is the estimation method presented in this paper, other useful estimation methods are available. The MHE minimizes model mismatch by dynamic optimization of certain unmeasured drilling parameters, such as mud density and friction factor. Furthermore, the model may be occasionally updated or tuned by periodic downhole measurements to increase accuracy. 


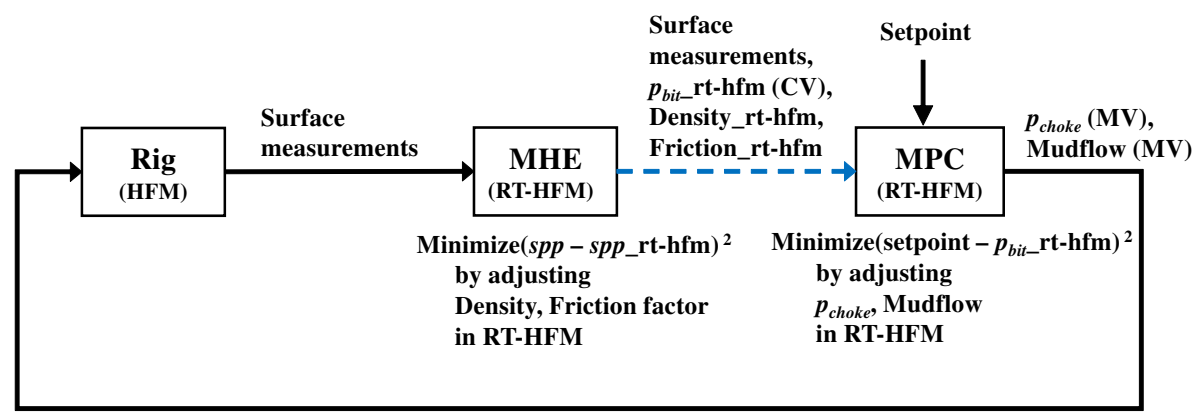

Figure 4: Semi-Closed loop control configuration - Bottomhole pressure is estimated by Moving horizon estimator

If real-time BHP measurements are available, a full-closed loop configuration may be employed. This type of system is presented in Figure 5. Note that, even though bottom hole measurements are available in real time, an estimator is still present in this configuration, since it is needed to estimate unmeasured drilling parameters such as mud density or friction factor. Because actual BHP measurements are used in the MHE calculation, the resulting estimated quantities are more reliable than those of the semi-closed loop case in Figure 4. The RT-HFM is continuously updated with the estimated parameters to increase the accuracy and reliability of the controller. We note here that, while various telemetry systems can supply real time BHP measurements, varying quality and quantity of real-time data are available from these different schemes. Some downhole data is subject to transmission delays on the order of at least a few seconds and delivery of the data may be subject to deprioritization depending on what other data is occupying the limited transmission channel. Other data ceases to flow when mud pumps are shut off or when pipe connections are made. These factors introduce uncertainty into the control process and place more reliance on model-based estimates. High-speed telemetry provided by wired drill pipe overcomes many of these limitations and provides more timely and abundant data for full-closed loop control [33]. Although some relatively short latency of data transmission can be introduced to the high-speed telemetry system, which is dependent on system configuration, we assume in the case study that the whole 


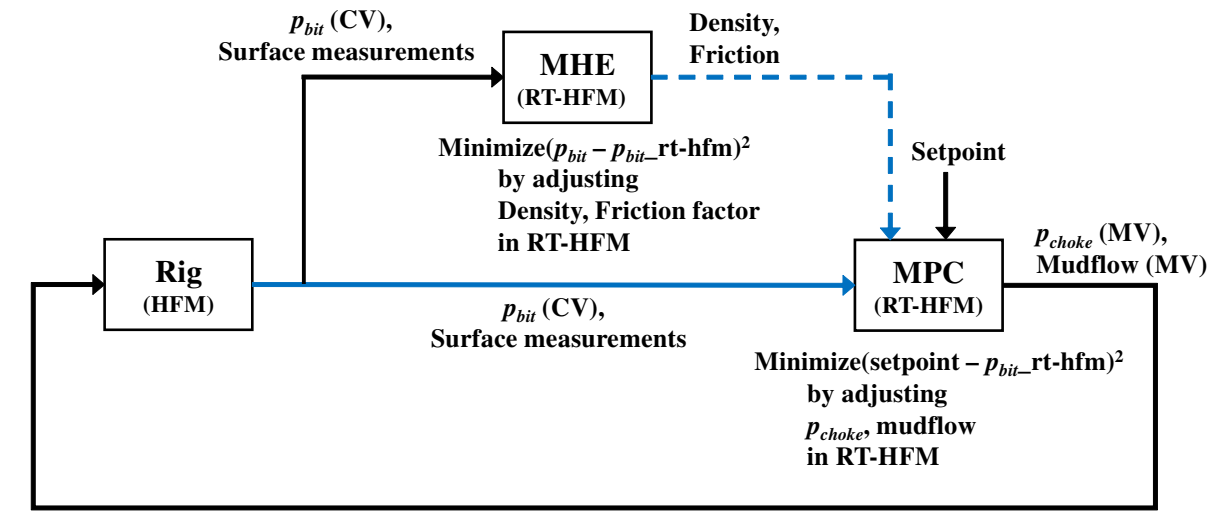

Figure 5: Full-Closed loop control configuration - Bottomhole pressure is directly measured and transmitted by bottomhole sensor and high speed telemetry. Friction factors are estimated for MPC model calibration

high-speed data transmission system operates in an idealized manner and we ignore this latency.

\section{Model Based Control and Estimation}

MPC calculations predict the future behavior of the process by evaluating the process model (in this case the RT-HFM) at the current time step. The MPC determines the sum of squared error between the setpoint trajectory and model prediction values throughout the prediction horizon and performs the control calculation by solving the quadratic programming (QP) objective function to find the optimal sequences of process inputs (MVs). The first value of the MV sequence is applied to the process and repeats the entire cycle for every time step.

The MHE algorithm shares this main concept with MPC. It calculates the unknown parameters in the model by solving the QP objective function that mainly includes the model errors. The objective function of MHE refers to the past data of measurements and model results while the MPC refers to the future model prediction and setpoint. Convergence proofs for this method of optimizing control are well-established and are not repeated here [34, 35]. 
The objective functions associated with MHE and MPC are shown in Equations (13) and (19), and the parameter descriptions are shown in Table 3 and 4, respectively. The model equations used in MPC and MHE simulations (appearing in Equations (13) and (19) as $f, g$, and $h$ ) are the governing equations of RT-HFM which are discussed in section 2.3 and 2.4.

$$
\begin{array}{ll}
\min _{\Delta \boldsymbol{P}} & \Phi=\left(\boldsymbol{Y}_{p}-\boldsymbol{Y}_{m}\right)^{T} \boldsymbol{W}\left(\boldsymbol{Y}_{p}-\boldsymbol{Y}_{m}\right)+\Delta \boldsymbol{P}^{T} \boldsymbol{V} \Delta \boldsymbol{P} \\
\text { s.t. } & 0=f(\dot{x}, x, y, p, d, u) \\
& 0=g(x, y, p, d, u) \\
& 0 \leq h(x, y, p, d, u)
\end{array}
$$

where $\boldsymbol{Y}_{p}$ and $\boldsymbol{Y}_{m}$ are the column vectors for measurement values and the model output values from the time step $(k-1)$ to $(k-N) . \Delta \boldsymbol{P}$ is the column vector for movement of the parameter adjustment for the past estimation horizon $(N)$, from the time step $(k-1)$ to $(k-N) . h$ and $i$ denote the number of SVs (State Variables) and EPs (Estimated Parameters), respectively. The MHE configuration for this study has two SVs and two EPs shown in Table 5 .

$$
\begin{gathered}
\boldsymbol{Y}_{p}=\operatorname{col}\left\{y_{1_{p}}(k-1), y_{1_{p}}(k-2), \cdots, y_{1_{p}}(k-N),\right. \\
y_{2_{p}}(k-1), y_{2_{p}}(k-2), \cdots, y_{2_{p}}(k-N), \\
\cdots, \\
\left.y_{h_{p}}(k-1), y_{h_{p}}(k-2), \cdots, y_{h_{p}}(k-N)\right\} \\
\boldsymbol{Y}_{m}=\operatorname{col}\left\{y_{1_{m}}(k-1), y_{1_{m}}(k-2), \cdots, y_{1_{m}}(k-N),\right. \\
y_{2_{m}}(k-1), y_{2_{m}}(k-2), \cdots, y_{2_{m}}(k-N), \\
\ldots, \\
\left.y_{h_{m}}(k-1), y_{h_{m}}(k-2), \cdots, y_{h_{m}}(k-N)\right\}
\end{gathered}
$$




$$
\begin{aligned}
\Delta \boldsymbol{P}=\operatorname{col}\{ & \Delta p_{1}(k-1), \Delta p_{1}(k-2), \cdots, \Delta p_{1}(k-N), \\
& \Delta p_{2}(k-1), \Delta p_{2}(k-2), \cdots, \Delta p_{2}(k-N), \\
& \cdots \\
& \left.\Delta p_{i}(k-1), \Delta p_{i}(k-2), \cdots, \Delta p_{i}(k-N),\right\}
\end{aligned}
$$

where, $\Delta p(k-N)=p(k-N)-p(k-N+1)$ denotes the movement size of EP in each time step throughout the estimation horizon $(N)$. $\boldsymbol{W}$ and $\boldsymbol{V}$ are the diagonal weighting matrices for multiple state variables and estimated parameters, as follows:

$$
\begin{gathered}
\boldsymbol{W}=\operatorname{diag}\left\{w_{y_{1}}(k-1), w_{y_{1}}(k-2), \cdots, w_{y_{1}}(k-N),\right. \\
w_{y_{2}}(k-1), w_{y_{2}}(k-2), \cdots, w_{y_{2}}(k-N), \\
\cdots, \\
\left.w_{y_{h}}(k-1), w_{y_{h}}(k-2), \cdots, w_{y_{h}}(k-N)\right\} \\
\boldsymbol{V}=\operatorname{diag}\left\{v_{p_{1}}(k-1), v_{p_{1}}(k-2), \cdots, v_{p_{1}}(k-N),\right. \\
v_{p_{2}}(k-1), v_{p_{2}}(k-2), \cdots, v_{p_{2}}(k-N), \\
\cdots, \\
\left.v_{p_{i}}(k-1), v_{p_{i}}(k-2), \cdots, v_{p_{i}}(k-N)\right\}
\end{gathered}
$$


Table 3: Summary of parameters used in QP objective function for MHE

\begin{tabular}{cl}
\hline Parameter & Description \\
\hline$\Phi$ & Objective function \\
$h, i$ & Number of state variables $(h)$ and estimated parameters $(i)$ \\
$N$ & Horizon length for MHE \\
$k$ & Current time step \\
$\boldsymbol{Y}_{p}, \boldsymbol{Y}_{m}$ & Measured CV $\left(y_{p}\right)$ and model result of CV $\left(y_{m}\right)$ \\
$\Delta \boldsymbol{P}$ & Moves of estimated parameters \\
$\boldsymbol{W}, \boldsymbol{V}$ & Weighting Matrices for state variables and parameters \\
$u, x, p, d$ & Model inputs $(u)$, states $(x)$, parameters $(p)$, \\
& and disturbance $(d)$ \\
$f, g, h$ & Model equation $(f)$, output function $(g)$, \\
& and inequality constraints $(h)$ \\
\hline
\end{tabular}

$$
\begin{aligned}
\min _{\Delta \boldsymbol{U}} & \Phi=\left(\hat{\boldsymbol{Y}}-\boldsymbol{Y}_{\text {ref }}\right)^{T} \boldsymbol{Q}\left(\hat{\boldsymbol{Y}}-\boldsymbol{Y}_{\text {ref }}\right)+\Delta \boldsymbol{U}^{T} \boldsymbol{R} \Delta \boldsymbol{U} \\
\text { s.t. } & 0=f(\dot{x}, x, y, p, d, u) \\
& 0=g(x, y, p, d, u) \\
& 0 \leq h(x, y, p, d, u)
\end{aligned}
$$

where $\hat{\boldsymbol{Y}}$ and $\boldsymbol{Y}_{\text {ref }}$ are the column vectors for model prediction values and the reference trajectory from the time step $(k+1)$ to $(k+P)$. $\Delta \boldsymbol{U}$ is the column vector for the control moves for the future control horizon $(M)$, from the time step $(k+1)$ to $(k+M) . m$ and $l$ denote the number of CVs and MVs, respectively. The MPC configuration for this study has one CV and two MVs summarized in Table 5. 


$$
\begin{gathered}
\hat{\boldsymbol{Y}}=\operatorname{col}\left\{\hat{y}_{1}(k+1), \hat{y}_{1}(k+2), \cdots, \hat{y}_{1}(k+P),\right. \\
\hat{y}_{2}(k+1), \hat{y}_{2}(k+2), \cdots, \hat{y}_{2}(k+P), \\
\cdots, \\
\left.\hat{y}_{m}(k+1), \hat{y}_{m}(k+2), \cdots, \hat{y}_{m}(k+P)\right\} \\
\boldsymbol{Y}_{\text {ref }}=\operatorname{col}\left\{y_{1_{\text {ref }}}(k+1), y_{1_{\text {ref }}}(k+2), \cdots, y_{1_{\text {ref }}}(k+P),\right. \\
y_{2_{r e f}}(k+1), y_{2_{r e f}}(k+2), \cdots, y_{2_{r e f}}(k+P), \\
\ldots, \\
\left.y_{m_{r e f}}(k+1), y_{m_{r e f}}(k+2), \cdots, y_{m_{r e f}}(k+P)\right\} \\
\Delta \boldsymbol{U}=\operatorname{col}\left\{\Delta u_{1}(k+1), \Delta u_{1}(k+2), \cdots, \Delta u_{1}(k+M),\right. \\
\Delta u_{2}(k+1), \Delta u_{2}(k+2), \cdots, \Delta u_{2}(k+M), \\
\ldots, \\
\left.\Delta u_{l}(k+1), \Delta u_{l}(k+2), \cdots, \Delta u_{l}(k+M),\right\}
\end{gathered}
$$

where, $\Delta u(k+M)=u(k+M)-u(k+M-1)$ denotes the movement size of MV in each time step throughout the control horizon $(M) . \boldsymbol{Q}$ and $\boldsymbol{R}$ are the diagonal weighting matrices for multiple CVs and MVs, as follows:

$$
\begin{gathered}
\boldsymbol{Q}=\operatorname{diag}\left\{q_{y_{1}}(k+1), q_{y_{1}}(k+2), \cdots, q_{y_{1}}(k+P),\right. \\
q_{y_{2}}(k+1), q_{y_{2}}(k+2), \cdots, q_{y_{2}}(k+P), \\
\cdots, \\
\left.q_{y_{m}}(k+1), q_{y_{m}}(k+2), \cdots, q_{y_{m}}(k+P)\right\} \\
\boldsymbol{R}=\operatorname{diag}\left\{r_{u_{1}}(k+1), r_{u_{1}}(k+2), \cdots, r_{u_{1}}(k+M),\right. \\
r_{u_{2}}(k+1), r_{u_{2}}(k+2), \cdots, r_{u_{2}}(k+M), \\
\cdots, \\
\left.r_{y_{l}}(k+1), r_{y_{l}}(k+2), \cdots, r_{u_{l}}(k+M)\right\}
\end{gathered}
$$


Table 4: Summary of parameters used in QP objective function for MPC

\begin{tabular}{cl}
\hline Parameter & Description \\
\hline$\Phi$ & Objective function \\
$m, l$ & Number of $\operatorname{CVs}(m)$ and $\operatorname{MVs}(l)$ \\
$P, M$ & Prediction horizon $(P), \operatorname{Control}$ horizon $(M)$ \\
$k$ & Current time step \\
$\hat{\boldsymbol{Y}}$ & Predicted CV value of dynamic model \\
$\hat{\boldsymbol{Y}}_{r e f}$ & Desired set point trajectory in the prediction horizon \\
$\Delta \boldsymbol{U}$ & Control moves of MV in the control horizon \\
$\boldsymbol{Q}, \boldsymbol{R}$ & Weighting Matrices for CVs and MVs \\
$u, x, p, d$ & Model inputs $(u)$, states $(x)$, parameters $(p)$, \\
& and disturbance $(d)$ \\
$f, g, h$ & Model equation $(f)$, output function $(g)$, \\
& and inequality constraints $(h)$ \\
\hline
\end{tabular}

Table 5: Variable configuration of MPC and MHE

\begin{tabular}{|c|c|c|c|c|c|c|c|c|}
\hline \multirow[t]{3}{*}{ Case } & \multicolumn{4}{|c|}{$\mathrm{MPC}$} & \multicolumn{4}{|c|}{ MHE } \\
\hline & \multirow{2}{*}{$\begin{array}{l}\text { CV } \\
y_{1}\end{array}$} & \multicolumn{2}{|c|}{ MV } & \multirow[t]{2}{*}{ DV } & \multicolumn{2}{|c|}{ SV } & \multicolumn{2}{|c|}{ EP } \\
\hline & & $u_{1}$ & $u_{2}$ & & $y_{1}$ & $y_{2}$ & $p_{1}$ & $p_{2}$ \\
\hline Normal drilling & $p_{b i t}$ & $p_{\text {choke }}$ & $q_{p}$ & & spp & $p_{b i t}$ & $f_{a}$ & $f_{d}$ \\
\hline Pipe connection & $p_{b i t}$ & $p_{\text {choke }}$ & & $q_{p}$ & spp & $p_{b i t}$ & $f_{a}$ & $f_{d}$ \\
\hline Density displacement & $p_{b i t}$ & $p_{\text {choke }}$ & $q_{p}$ & $\rho_{m u d}$ & spp & $p_{b i t}$ & $f_{a}$ & $f_{d}$ \\
\hline
\end{tabular}

The horizon lengths and weighting factors for both MPC and MHE are obtained by manual tuning based on operational preference and experience, and are reported in Tables 6 and 7 . The single value of the weighting factor is used for the each elements of the diagonal weighting matrix. There are research studies that propose the methods of finding optimal weighting matrices [36, 37, 38]. 
Table 6: Horizon lengths and weighting factors for MPC

\begin{tabular}{lrrrrr}
\hline Case & \multicolumn{5}{c}{ MPC } \\
\cline { 2 - 6 } & $P^{*}$ & $M^{*}$ & $q_{y_{1}}$ & $r_{u_{1}}$ & $r_{u_{2}}$ \\
\hline Normal drilling & 40 & 15 & 1000 & 100 & 0.1 \\
Pipe connection & 10 & 10 & 1000 & 100 & $0(D V)$ \\
Density displacement & 300 & 240 & 1000 & 100 & 0.05 \\
\hline
\end{tabular}

* $P$ and $M$ represent a prediction and a control horizon, respectively.

Table 7: Horizon lengths and weighting factors for MHE

\begin{tabular}{|c|c|c|c|c|c|c|c|c|}
\hline \multirow[t]{3}{*}{ Case } & \multicolumn{8}{|c|}{ MHE } \\
\hline & \multirow[b]{2}{*}{$N^{*}$} & \multicolumn{3}{|c|}{ semi } & \multicolumn{4}{|c|}{ full } \\
\hline & & $w_{y_{1}}$ & $v_{p_{1}}$ & $v_{p_{2}}$ & $w_{y_{1}}$ & $w_{y_{2}}$ & $v_{p_{1}}$ & $v_{p_{2}}$ \\
\hline Normal drilling & 25 & 1 & 500 & 200 & 1000 & 2000 & 2000 & 500 \\
\hline Pipe connection & 30 & 1000 & 1000000 & 1 & 100 & 500 & 10000 & 10000 \\
\hline Density displacement & 120 & 1 & 500 & 200 & 1 & 100 & 500 & 200 \\
\hline
\end{tabular}

* $N$ represents an estimation horizon.

5. Case Studies

In this section, the three MPD operating scenarios used to test the RT-HFMbased controller are described. In each test case, the response of the well pressure is simulated by an HFM. As mentioned previously, this HFM has been shown through field experience to accurately represent field conditions in the tested regime [31]. Referring to Figures 4 and 5, the HFM simulates those physical processes denoted by the "Rig" block in the diagrams (including the physical well being drilled). A vertical wellbore profile has been chosen to reproduce a recent MPD operation in the North Sea [39], with model parameters as shown in Table 8. 
Table 8: Wellbore Conditions

\begin{tabular}{lll}
\hline Parameter & Value (AES) & Value (SI) \\
\hline Well depth & $12,349 \mathrm{ft}$ & $3,764 \mathrm{~m}$ \\
Riser inner diameter & $9.66 \mathrm{in}$ & $0.25 \mathrm{~m}$ \\
Water depth & $731.6 \mathrm{ft}$ & $223 \mathrm{~m}$ \\
Casing inner diameter & $8.535 \mathrm{in}$ & $0.216 \mathrm{~m}$ \\
Casing depth & $12,349 \mathrm{ft}$ & $3,764 \mathrm{~m}$ \\
Drill string average outer diameter & $5.0 \mathrm{in}$ & $0.127 \mathrm{~m}$ \\
Pore pressure gradient & $11.0 \mathrm{ppg}$ & $1,330 \mathrm{~kg} / \mathrm{m}^{3}$ \\
Fracture pressure gradient & $16.0 \mathrm{ppg}$ & $1,927 \mathrm{~kg} / \mathrm{m}^{3}$ \\
Initial mud density & $12.4 \mathrm{ppg}$ & $1,490 \mathrm{~kg} / \mathrm{m}^{3}$ \\
Mud temperature & $122{ }^{\circ} \mathrm{F}$ & $50{ }^{\circ} \mathrm{C}$ \\
\hline
\end{tabular}

The performance of the controller for each scenario was observed for both semi- and full-closed loop configurations. In the drilling industry, the full-closed loop configuration is a less common option because a real-time feedback signal from the well bottom is frequently not available; the majority of drilling operations presently use a semi-closed loop configuration, where sensor data may be provided at infrequent or irregular intervals. However, the full-closed loop configuration is at times available and the level of control achieved with this configuration represents a best-case scenario to which we can compare control achieved by semi-closed loop. Therefore, the purpose of this comparison is not to show that one configuration is superior to the other (full-closed loop control is certainly the ideal case), but rather to determine whether the model of the system provided by the RT-HFM can enable the controller in a semi-closed loop configuration achieve a level of control similar to that in the full-closed loop configuration. The semi-closed loop configuration relies more on the model equations than the full-closed loop configuration in the absence of the BHP measurement; thus, by comparing the two, we are able to measure the effectiveness of the model.The performance comparisons between various controllers such as 
PID vs. Hammerstein-Wiener MPC [20] and LFM MPC vs. HFM MPC [30] have been investigated in previous research.

Both semi-closed loop and full-closed loop control schemes were tested under the following scenarios:

1. Normal drilling (mud flow, drillstring rotation, formation penetration)

2. Pipe connection (cessation of mud flow and drillstring rotation)

3. Mud density displacement over a fixed period of time

Prior to each of the scenarios listed above, an initial model calibration step is performed. This step uses the MHE exclusively, and it is assumed that both BHP $\left(p_{b i t}\right)$ and SPP (standpipe pressure, spp) measurements are available during this period. In common practice, the BHP measurement is available from downhole sensors at various points in time for model calibration. The friction factors in the annulus and drillstring $\left(f_{a}\right.$ and $\left.f_{d}\right)$ are estimated based on both BHP and SPP by minimizing the differences between the model and the measured value. The estimated parameters (EPs), which are $f_{a}$ and $f_{d}$, are updated in the MPC model to allow prediction with improved model accuracy.

After the model calibration period, the three control scenarios use the MHE and MPC in parallel for real-time estimation and control. For these three control scenarios, the variable configurations in the MPC are changed based on the scenarios, while the MHE uses the same variable configurations for all scenarios (Table 5). The detailed description of each scenario is shown in the following subsections

\subsection{Normal Drilling}

BHP control provides the ability to drill in narrow pressure profile wells in addition to optimizing the ROP [40]. Thus, the controller's ability to respond appropriately (e.g., quickly but with a minimum of overshoot) to setpoint changes is important when drilling within these tight pressure limits. To quantify the controller's ability to track setpoint changes, the "normal" drilling scenario introduces three different step changes in setpoint. 
In a normal drilling scenario both the choke pressure ( $\left.p_{\text {choke }}\right)$ and drilling fluid flow $\left(q_{p}\right)$ can be manipulated by the controller. Once key unmeasured variables, including system friction factors $\left(f_{a}, f_{d}\right)$, are initially calibrated in the model by the model calibration procedure, the MPC algorithm adjusts the manipulated variables to minimize the difference between the set point and the calculated BHP (in semi-closed loop) or measured BHP (in full-closed loop) across the prediction horizon. This accurately drives the BHP to the set point while complying with any user-provided constraints, such as the maximum rate of change for the manipulated variables such as choke pressure ( $\left.p_{\text {choke }}\right)$ and mud flowrate $\left(q_{p}\right)$.

\subsection{Pipe Connection}

During a pipe connection procedure, the normal control processes must be modified to accommodate the addition of more pipe. As the drill bit deepens during the drilling process additional pipe lengths are periodically added to the drill string. The addition of pipe is typically required every one to three hours but is dependent on the pipe stand length and the ROP [41]. During this pipe connection it is necessary to ramp the drilling fluid flow rate to zero, attach the new pipe length, and then bring the flow rate back up to normal conditions again. As the mud flow rate is brought to zero the controller then relies solely on the choke pressure until the pipe connection is complete. However, because pipe connection is a planned event and the ramp rate is known in advance, the ramp rate can be passed into the MPC acting as a measured disturbance variable (DV) so that the changing mud flow can be considered in the BHP predictions of the MPC and improve control accuracy during the pipe connection period.

\subsection{Mud Density Displacement}

At the end of the MPD operation it is optimal to shut off the choke valve. To reduce reliance on the choke pressure in the control scheme, higher density mud is fed to the bottom hole. This higher density mud serves as a less accurate substitute for the choke valve because it exerts a higher pressure on the open 
hole so that the choke manifold can be released and disengaged from BHP management. In this scenario, the mud density changes over a period, thus allowing for a slow opening of the choke valve. As the density changes, the controller accounts for this change in system dynamics as it manages the BHP. This scenario differs from the pipe connection scenario in that the controller adjusts to rely solely on the drilling fluid flow, whereas for pipe connection the drilling fluid flow must be ramped down. Throughout the period of density transition and choke valve ramp up, the estimator is relied upon to provide accurate friction factors that keep the model accurate despite the changing conditions.

\section{Results and Discussions}

This section presents the results of the case studies. The control performances of both semi-closed loop and full-closed loop configurations are shown and quantified using ISE (integral of squared error) index shown in Table 9.

\subsection{Normal Drilling}

Figures 6 and 7 display the results of the normal drilling case study for the semi-closed loop and full-closed loop configurations, respectively. Although the results appear to be nearly equivalent, the two cases are important to compare and contrast. Figure 6 represents the case where downhole measurements are unavailable; therefore, there is an expected offset between the model-predicted values and the measured values. In an actual drilling process without any bottomhole measurements, there would likely be an even more substantial offset between the true and estimated BHP. Large sources of potential error include unknown temperature profiles along the drillstring annulus and non-Newtonian fluid properties that are influenced by high pressures and varying temperatures. In Figure 7 the bottomhole conditions are directly measured and transmitted in real-time to the surface. This allows for offset-free control, which is the most desirable condition. However, even with downhole sensors and near-instantaneous 
feedback, there are likely to be periods of time when the telemetry system is not available or when there is sensor error. Highlighting both case studies shows that MPC can be used with or without the bottomhole sensors with an accurate predictive model that is calibrated to the drilling process. The suitability of a semi-closed loop approach using real-time model-based control as opposed to a full closed loop approach depends upon the tolerance of the specific application to the presence of an offset.

In the semi-closed loop case the BHP is calculated by the MHE, minimizing the difference between measured and modeled SPP. It is assumed that bottom hole conditions are communicated to the surface at infrequent intervals during the drilling process. This is compared to the full-closed loop conditions where BHP measurements are regular and frequent. The model parameters $\left(f_{a}\right.$ and $\left.f_{d}\right)$ are calibrated during the model calibration period. This calibration is observed in Figures 6 and 7 between 0 and 200 seconds. The model calibration period is shown in Figure 8 separately in magnified time scale. The MPC controller is activated after 200 seconds. The control movements of the MVs ( $p_{\text {choke }}$, $\left.q_{p}\right)$ are observed in Figures $6 \mathrm{c}$ and $7 \mathrm{c}$. Figures $6 \mathrm{~b}$ and $7 \mathrm{~b}$ show the estimated friction factors $\left(f_{a}\right.$ and $\left.f_{d}\right)$. The BHP control is more effective in a full-closed loop scenario as the controller is able to use actual bottomhole conditions to inform the control moves. However, it is of interest that the improvement in control performance observed in the full-closed loop case is minor and that the full-closed loop scenario brought the BHP about 0.5 bar closer to the setpoint as compared to the semi-closed loop scenario. While this is not an exhaustive survey across a multitude of well conditions, it is indicative of the value and effectiveness of using a semi-closed loop system that employs a RT-HFM. As can be seen in Figures 6 and 7, very similar control moves were made, and the resulting BHP measurements differed by less than one bar. 

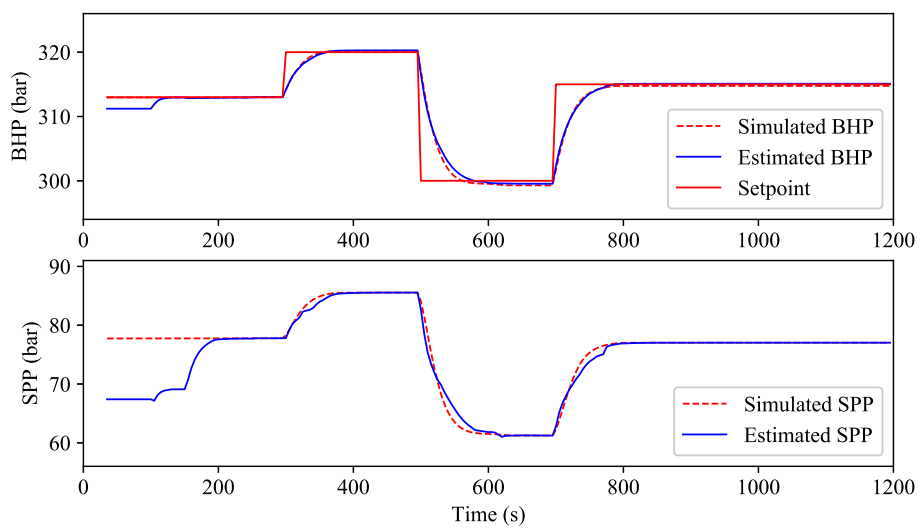

(a) Bottomhole pressure (CV) and Standpipe pressure
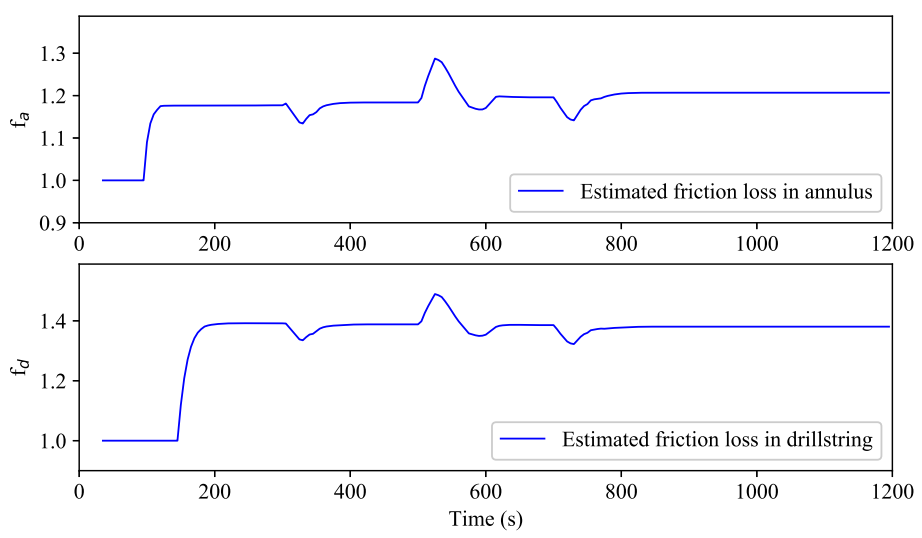

(b) Friction factors in annulus and drill string

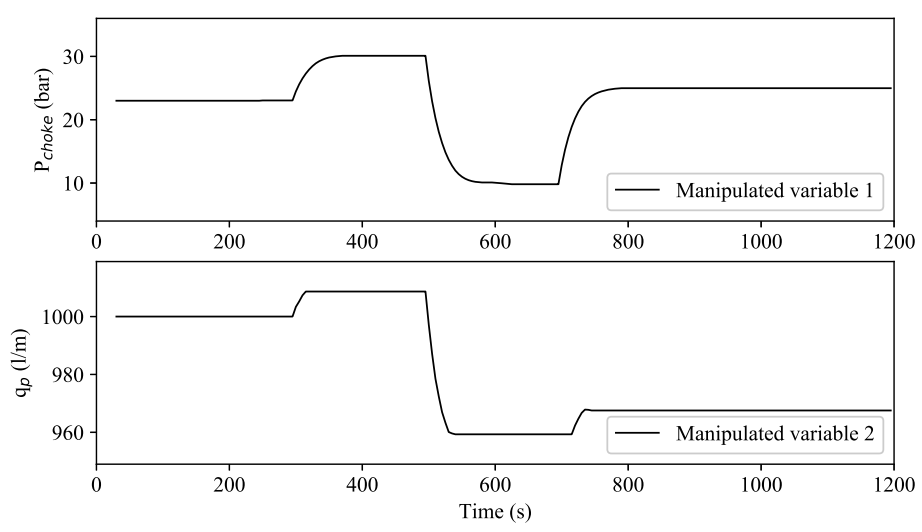

(c) Choke pressure (MV1) and Mud flowrate (MV2)

Figure 6: Control performance for normal drilling scenario (Semi-closed loop) 

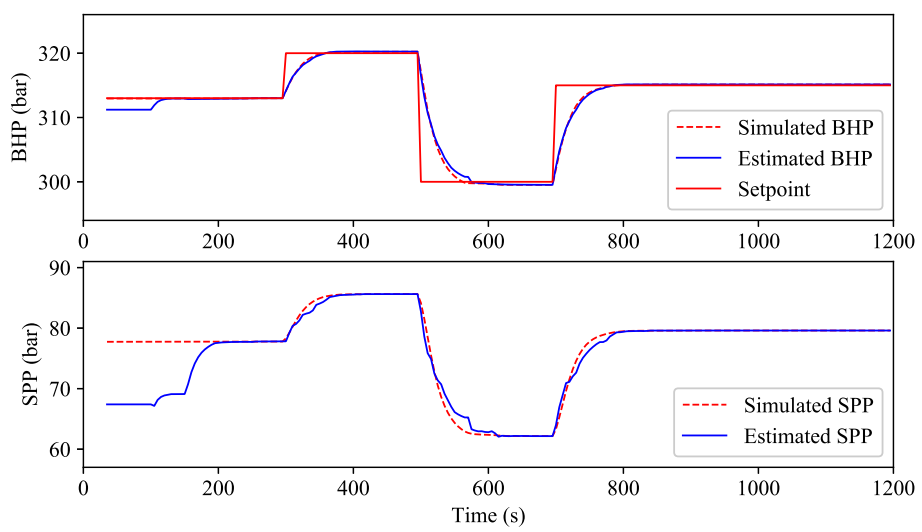

(a) Bottomhole pressure (CV) and Standpipe pressure
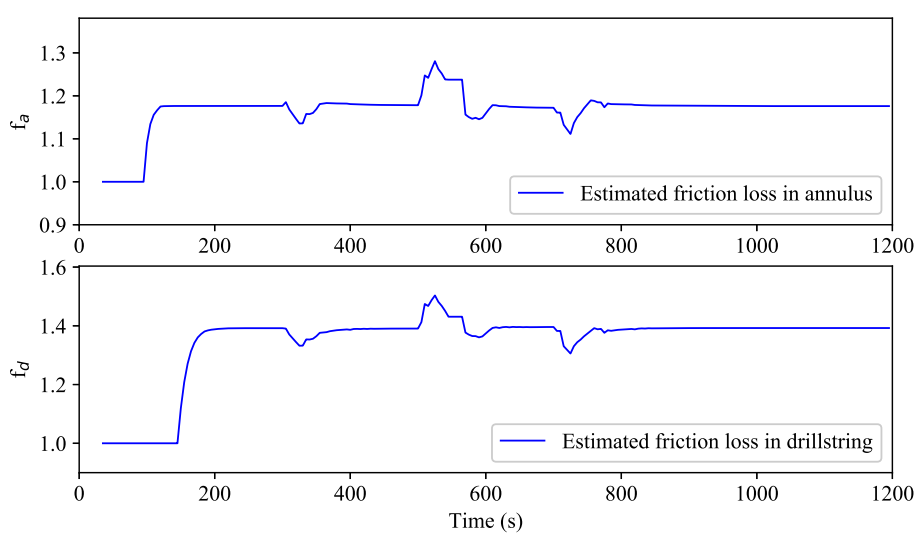

(b) Friction factors in annulus and drill string

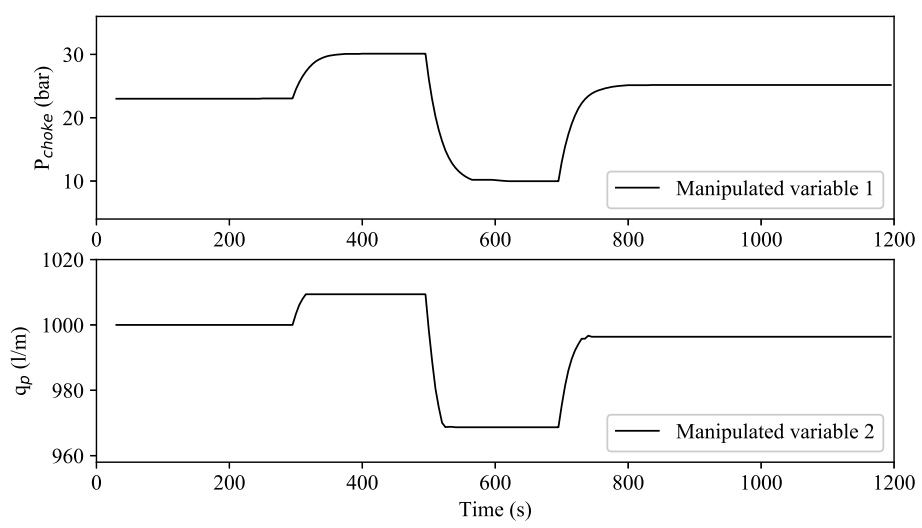

(c) Choke pressure (MV1) and Mud flowrate (MV2)

Figure 7: Control performance for normal drilling scenario (Full-closed loop) 
Figure 8 presents the results of the MHE for the initial model calibration of the annulus and drillstring friction factors. The MHE first estimates the annulus friction factor $\left(f_{a}\right)$ at 150 seconds by minimizing the difference between the RT-HFM BHP and the HFM BHP. At 400 seconds the MHE finds the drill string friction factor $\left(f_{d}\right)$ by minimizing the difference between the RT-HFM SPP and the HFM SPP. Once both friction factors are estimated, the model is ready to be used effectively for control. After this initial model calibration step, the MPC controller is turned on with the updated friction factors for the subsequent control scenarios. While the controller turns on, the friction factors are continuously adjusted by the MHE in parallel with MPC in real-time. 

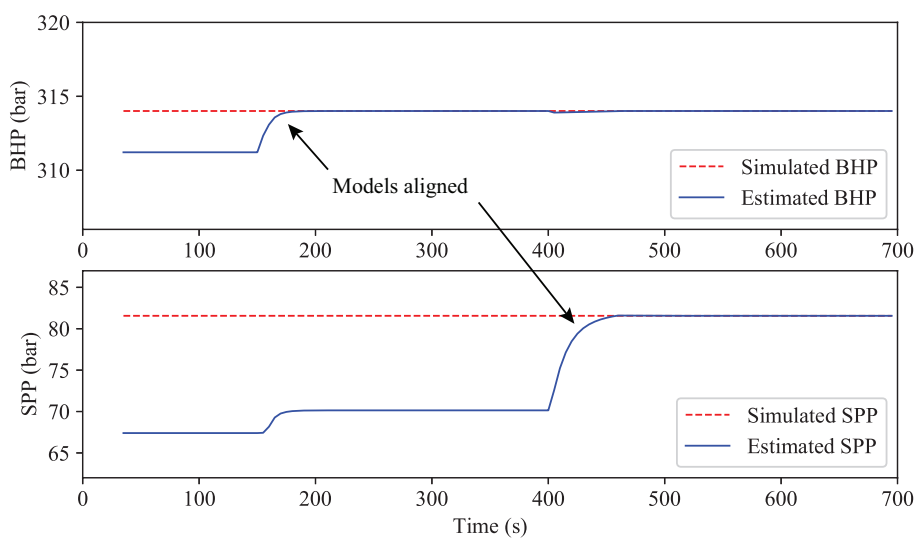

(a) Bottomhole pressure (CV) and Standpipe pressure
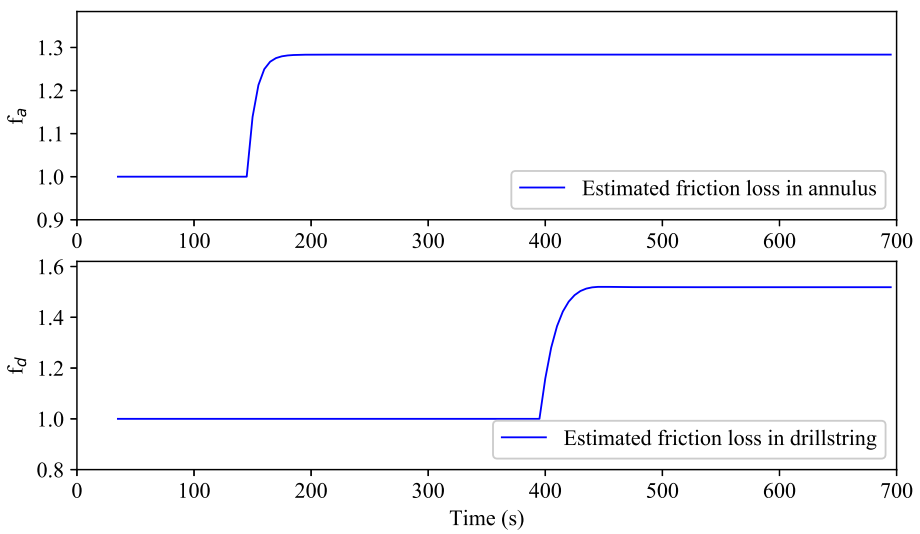

(b) Friction factors in annulus and drill string

Figure 8: Model calibration using MHE

\subsection{Pipe Connection}

The pipe connection procedure results are shown in Figures 9 and 10. During the pipe connection procedure, mud flowrate moves through a wider operational range from the range of normal drilling to a zero flow rate which produces greater model mismatch than the normal drilling scenario. According to the settings and models of this study, the primary factor influencing the model mismatch is the mud flowrate because the friction factor of the drill string and annulus is only important when the mud is flowing. At the beginning of the case study, 
the model calibration proceeds until the MPC control starts at 400 seconds. From 600 seconds, mud flowrate starts ramping down and stays at the zero flowrate for about 300 seconds until the new segment of a drill string is added. The mud flow rate is then ramped back up to the normal drilling range $(1000$ $l / \min )$. As the mud flow ramps down, the BHP is maintained by compensatory moves in the choke pressure. Because it is a planned change in the mud flow, the ramp down is communicated to the predictive controller and the controller determines effective moves to maintain a steady bit pressure through the pipe connection procedure. The MHE continuously adjusts the annulus and drill string friction factors to match the BHP or SPP, depending on the control mode. Figures 9 and 10 show the results of the semi-closed loop and full-closed loop control mode, respectively. Although the mud flowrate is varied greatly, both control modes show acceptable control performance maintaining the BHP within \pm 1 bar deviation. However, the semi-closed loop mode shows slightly worse control performance than the full-closed loop mode after mud flowrate ramps up completely because the friction factors are not stabilized their original values. The objective of MHE to minimize model and process discrepancies is satisfied for the semi-closed loop mode by minimizing the SPP difference between the HFM and RT-HFM instead of BHP difference in full-closed loop. Thus, the 0.5 bar gap between 'Simulated BHP (HFM)' and 'Estimated BHP (RT-HFM)' is observed in Figure 9a but not shown in Figure 10a. 

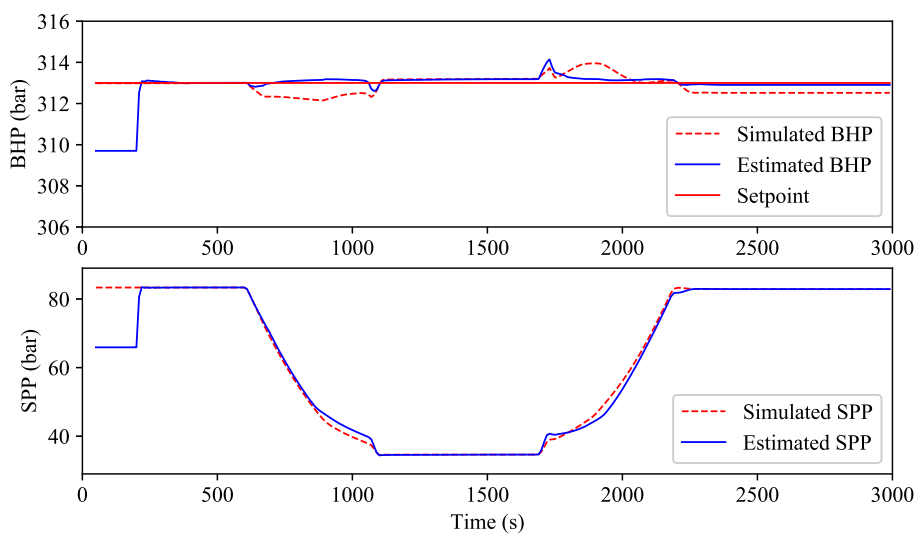

(a) Bottomhole pressure (CV) and Standpipe pressure
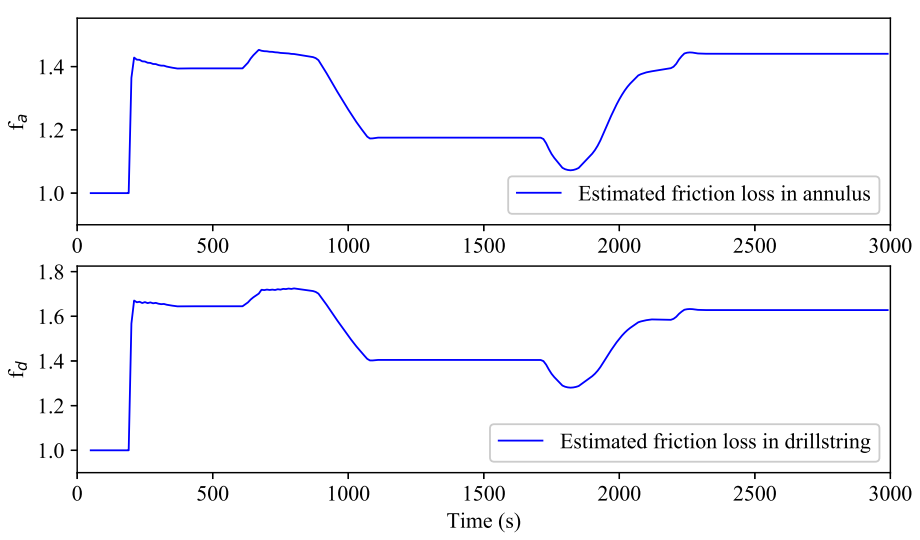

(b) Friction factors in annulus and drill string

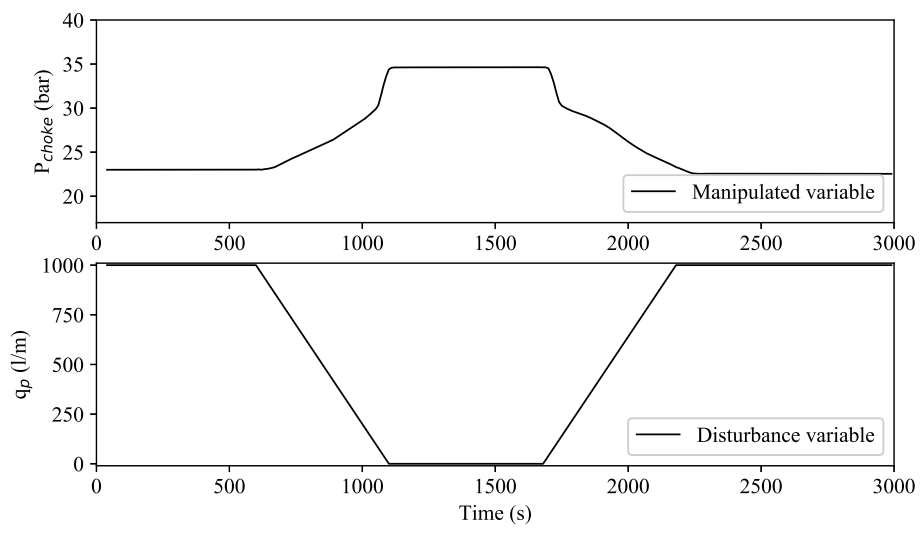

(c) Choke pressure (MV) and Mud flowrate (DV)

Figure 9: Control performance for pipe connection scenario (Semi-closed loop) 

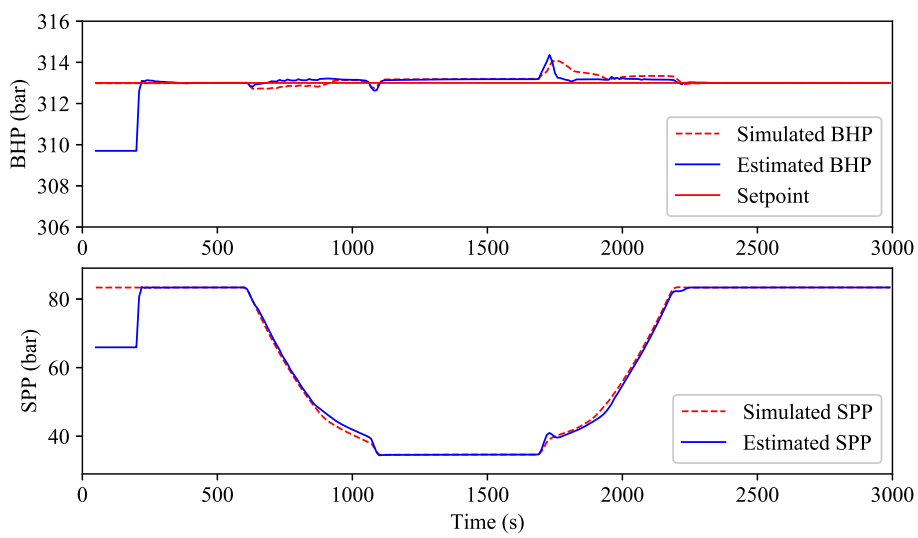

(a) Bottomhole pressure (CV) and Standpipe pressure
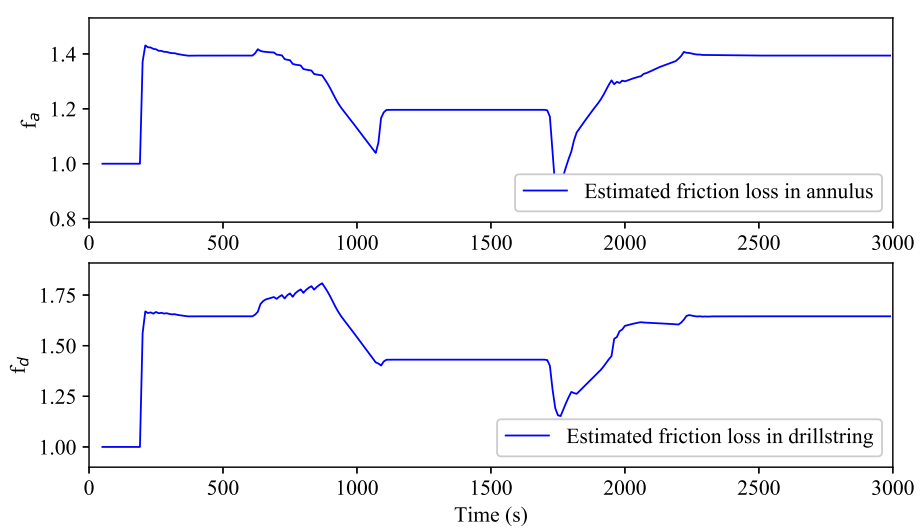

(b) Friction factors in annulus and drill string

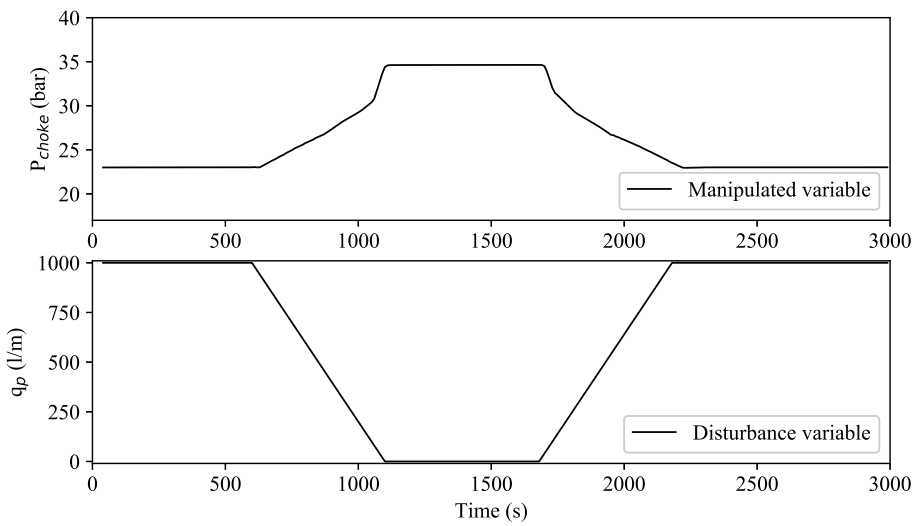

(c) Choke pressure (MV) and Mud flowrate (DV)

Figure 10: Control performance for pipe connection scenario (Full-closed loop) 


\subsection{Mud Density Displacement}

The results in Figures 11 and 12 demonstrate the impact of changes in drilling fluid density on the estimated friction factor and the resultant changes in the choke pressure and drilling fluid flow. The differences between a semi-closed and full-closed loop mud density displacement scenario are also displayed. The drilling fluid density change is observed at 0.5 hours as the density is stepped up from 1.5 S.G. to 1.6 S.G. The choke valve is subsequently ramped down over a 2.5 hour period between 0.5 and 3 hours. It is observed that because of the aforementioned system changes, the drilling fluid flow slowly decreases to further counteract the increase in density. This indicates that fully opening the choke valve does not provide enough pressure relief and the controller selectively relies on the drilling fluid flow to maintain control. Additionally, the standpipe pressure drops off substantially but the BHP stays high as a result of the higher density drilling fluid. In the full-closed loop configuration, the RT-HFM matches the simulated real world conditions more closely, which improves the quality of BHP control provided by the MPC controller. 

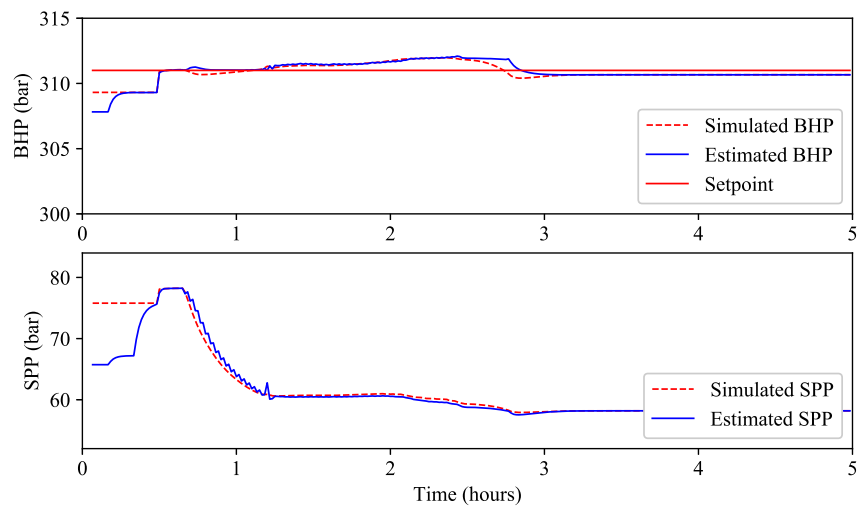

(a) Bottomhole pressure (CV) and Standpipe pressure

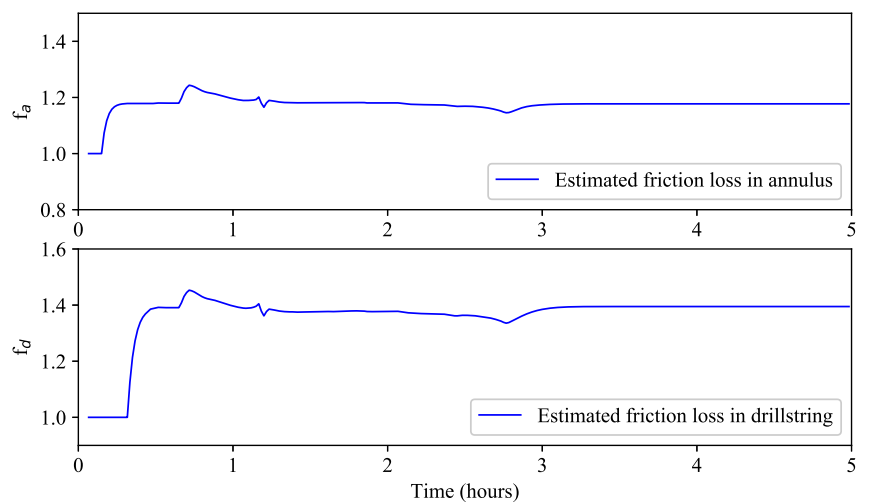

(b) Friction factors in annulus and drill string

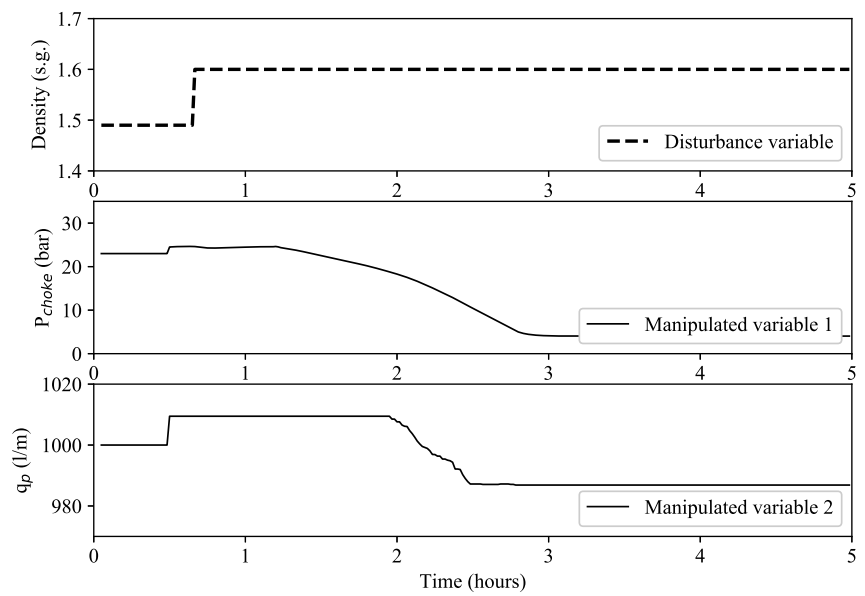

(c) Choke pressure (MV) and Mud flowrate (DV)

Figure 11: Control performance for mud density displacement scenario (Semi-closed loop) 

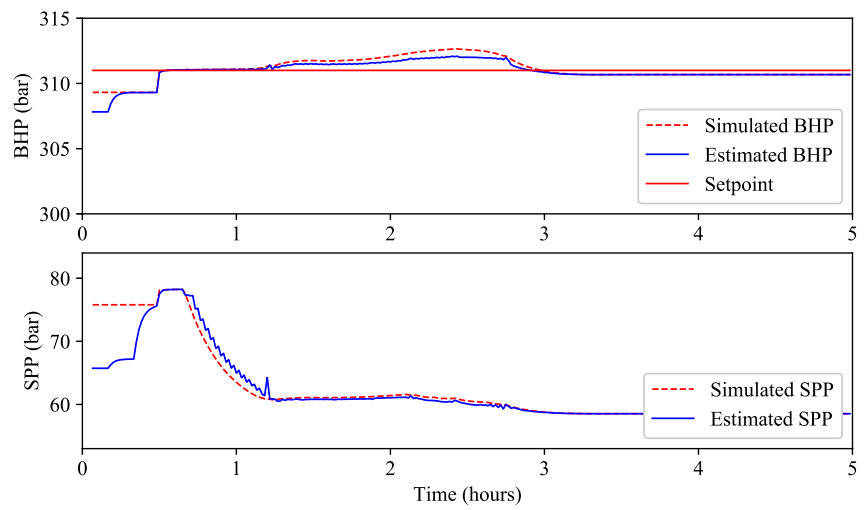

(a) Bottomhole pressure (CV) and Standpipe pressure

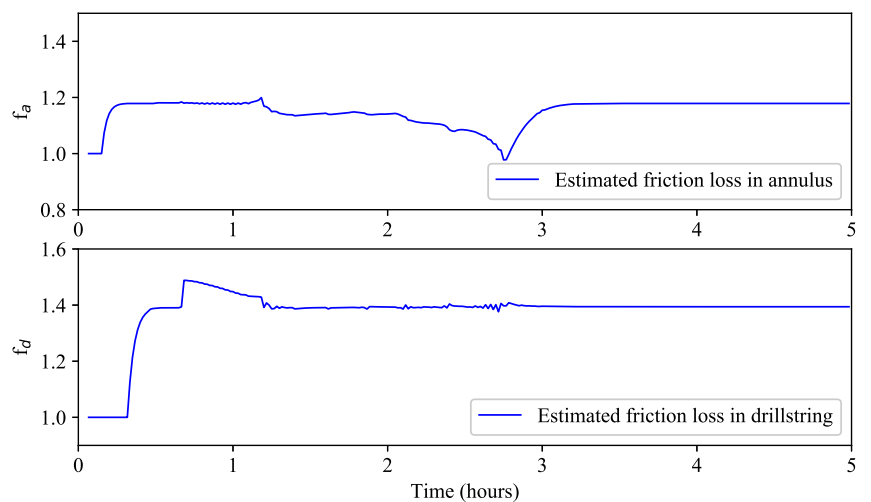

(b) Friction factors in annulus and drill string

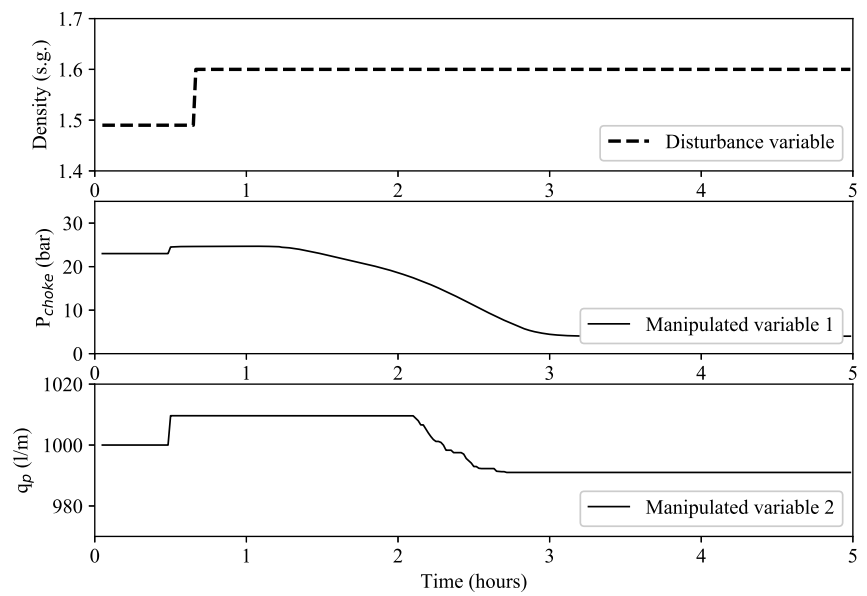

(c) Choke pressure (MV) and Mud flowrate (DV)

Figure 12: Control performance for mud density displacement scenario (Full-closed loop) 
Table 9: Control performance comparison in ISE index

\begin{tabular}{lrr}
\hline Case & \multicolumn{2}{c}{ ISE } \\
\cline { 2 - 3 } & Semi-closed loop & full-closed loop \\
\hline Normal drilling & 762.86 & 756.35 \\
Pipe connection & 53.64 & 17.14 \\
Density displacement & 64.62 & 58.39 \\
\hline
\end{tabular}

\section{Conclusions and Future Work}

This study represents the first implementation of a high-fidelity grade physicsbased model in a real-time control application using MPC. In the simulations reported herein, the model-based control schemes achieved tight controller performance that successfully maintained the BHP to within one bar of the set point during normal drilling, pipe connection, and mud density displacement operations. Although the results are obtained from the simulation environment under the noise-free condition, this responsive model performance validates our hypothesis that high-fidelity physics-based models can be successfully embedded in real-time control systems, and suggests the suitability of this model for use under real MPD conditions, including wells with tight pressure margins.

Moreover, the highly detailed model embedded in the estimator and controller provides advantages when operating in the relatively harsh oilfield drilling environment, since it allows for periods of sparse feedback communication that is characteristic of the environment, with minimum performance degradation. Our simulation studies have shown that in all three operational scenarios, the difference in controller response between a full-closed loop control scheme and a semi-closed loop is marginal. Future work should include optimization of tuning parameters to maximize controller performance, and testing on a broader suite of field conditions which include the measurement noise and unmeasured disturbances.

This work also lays the foundation for further work with more complex 
systems and control scenarios that leverage the power of MPC.

For example, although pressure and vibration control methods are evolving separately in the drilling industry, these should be integrated into a single research topic in the future as the technologies mature. A recent example of such multivariable control investigates ROP optimization combined with BHP control based on fundamental flow models [42]. In this work, the mutual effects of the drill string dynamics and hydraulics are considered. This topic should be revisited in view of the advances made on both research fronts.

\section{Acknowledgments}

The authors acknowledge the financial and technical assistance of SINTEF, The Foundation for Scientific and Industrial Research of Norway, in projects related to modeling and control design for automated drilling systems.

\section{References}

[1] J.-M. Godhavn, Control requirements for automatic managed pressure drilling system, SPE Drilling Completion 25 (03) (2010) 336-345, j2: SPE119442-PA. doi:10.2118/119442-PA.

[2] L. A. Carlsen, G. Nygaard, M. Nikolaou, Evaluation of control methods for drilling operations with unexpected gas influx, Journal of Process Control 23 (3) (2013) 306-316.

[3] J. Zhou, Ø. N. Stamnes, O. M. Aamo, G.-O. Kaasa, Adaptive output feedback control of a managed pressure drilling system, in: 47th IEEE Conference on Decision and Control, CDC 2008, December 9, 2008 - December 11, 2008, 2008.

[4] Z. Li, N. Hovakimyan, G.-O. Kaasa, Fast estimation and 11 adaptive control for bottomhole pressure in managed pressure drilling, in: 2011 IEEE International Symposium on Intelligent Control, ISIC 2011, September 28, 2011 - September 30, 2011, 2011. 
[5] S. J. Qin, T. A. Badgwell, A survey of industrial model predictive control technology, Control engineering practice 11 (7) (2003) 733-764.

[6] L. Beal, D. Hill, R. Martin, J. Hedengren, Gekko optimization suite, Processes 6 (8) (2018) 106.

[7] G.-Q. Zeng, X.-Q. Xie, M.-R. Chen, An adaptive model predictive load frequency control method for multi-area interconnected power systems with photovoltaic generations, Energies 10 (1840) (2017) 1-23. doi:10.3390/en10111840.

[8] T. Pedersen, J.-M. Godhavn, Linear multivariable control of underbalanced-drilling operations, SPE Drilling Completion 32 (04) (2017) 301-311, j2: SPE-185184-PA. doi:10.2118/185184-PA.

URL https://doi.org/10.2118/185184-PA

[9] R. A. Shishavan, C. Hubbell, H. D. Perez, J. D. Hedengren, D. S. Pixton, A. P. Pink, Multivariate control for managed-pressure-drilling systems by use of high-speed telemetry, SPE Journal 21 (02) (2016) 459-470, j2: SPE170962-PA. doi:10.2118/170962-PA.

URL https://doi.org/10.2118/170962-PA

[10] J. Mogster, J. M. Godhavn, L. Imsland, Using MPC for managed pressure drilling, Modeling, Identification and Control 34 (3) (2013) 131-138.

[11] A. Nikoofard, T. A. Johansen, H. Mahdianfar, A. Pavlov, Constrained mpc design for heave disturbance attenuation in offshore drilling systems, in: OCEANS-Bergen, 2013 MTS/IEEE, IEEE, 2013, pp. 1-7.

[12] A. Albert, O. M. Aamo, J. Godhavn, A. Pavlov, Suppressing pressure oscillations in offshore drilling: Control design and experimental results, IEEE Transactions on Control Systems Technology 23 (2) (2015) 813-819, iD: 1. doi:10.1109/TCST.2014.2332541. 
[13] M. G. Forbes, R. S. Patwardhan, H. Hamadah, R. B. Gopaluni, Model predictive control in industry: Challenges and Opportunities, IFAC PapersOnLine 48 (8) (2015) 531-538. doi:10.1016/j.ifacol.2015.09.022.

[14] G. Nygaard, G. Nævdal, Nonlinear model predictive control scheme for stabilizing annulus pressure during oil well drilling, Journal of Process Control 16 (7) (2006) 719-732.

[15] Ø. Breyholtz, G. Nygaard, M. Nikolaou, Automatic control of managed pressure drilling, in: 2010 American Control Conference, ACC 2010, June 30, 2010 - July 2, 2010, Proceedings of the 2010 American Control Conference, ACC 2010, IEEE Computer Society, 2010, pp. 442-447.

[16] A. Nandan, S. Imtiaz, Nonlinear model predictive control of managed pressure drilling, ISA Transactions 69 (2017) $307 \quad-314$. doi:https://doi.org/10.1016/j.isatra.2017.03.013.

[17] H. B. Siahaan, E. H. Vefring, M. Nikolaou, J. E. Gravdal, et al., Evaluation of Coordinated Control During Back Pressure MPD Operations, in: SPE Bergen One Day Seminar, Society of Petroleum Engineers, 2014.

[18] Ø. Breyholtz, G. H. Nygaard, H. Siahaan, M. Nikolaou, et al., Managed pressure drilling: A multi-level control approach, in: SPE Intelligent Energy Conference and Exhibition, Society of Petroleum Engineers, 2010.

[19] A. Nikoofard, T. A. Johansen, H. Mahdianfar, A. Pavlov, Design and comparison of constrained mpc with pid controller for heave disturbance attenuation in offshore managed pressure drilling systems, Marine Technology Society Journal 48 (2) (2014) 90-103.

[20] J. Park, T. Webber, R. A. Shishavan, J. D. Hedengren, Improved Bottomhole Pressure Control with Wired Drillpipe and Physics-Based Models, 2017, p. 13, j2: SPE-184610-MS. doi:10.2118/184610-MS.

URL https://doi.org/10.2118/184610-MS 
[21] M. Ławryńczuk, Nonlinear predictive control for Hammerstein-Wiener systems, ISA transactions 55 (2015) 49-62.

[22] T. Pedersen, J.-M. Godhavn, J. Schubert, Supervisory control for underbalanced drilling operations, IFAC-PapersOnLine 48 (6) (2015) 120-127.

[23] H. Cai, P. Li, C. Su, J. Cao, Double-layered nonlinear model predictive control based on Hammerstein-Wiener model with disturbance rejection, Measurement and Control 51 (7-8) (2018) 260-275.

[24] K. Patan, Two stage neural network modelling for robust model predictive control, ISA transactions 72 (2018) 56-65.

[25] G.-O. Kaasa, Ø. N. Stamnes, O. M. Aamo, L. S. Imsland, Simplified hydraulics model used for intelligent estimation of downhole pressure for a managed-pressure-drilling control system, SPE Drilling \& Completion, SPE-143097-PAdoi:10.2118/143097-PA.

[26] T. Pedersen, U. J. F. Aarsnes, J.-M. Godhavn, Flow and pressure control of underbalanced drilling operations using nmpc, Journal of Process Control 68 (2018) 73-85.

[27] D. Mayne, Robust and stochastic model predictive control: Are we going in the right direction?, Annual Reviews in Control 41 (2016) 184-192.

[28] J. Novák, P. Chalupa, Implementation aspects of embedded mpc with fast gradient method, International Journal of Circuits, Systems and Signal Processing.

[29] J. Petersen, R. Rommetveit, K. S. Bjørkevoll, J. Froyen, A general dynamic model for single and multi-phase flow operations during drilling, completion, well control and intervention, in: IADC/SPE Asia Pacific Drilling Technology Conference and Exhibition, Society of Petroleum Engineers, SPE-114688-MS, 2008. doi:10.2118/114688-MS. 
[30] A. N. Eaton, L. D. Beal, S. D. Thorpe, C. B. Hubbell, J. D. Hedengren, R. Nybø, M. Aghito, Real time model identification using multi-fidelity models in managed pressure drilling, Computers \& Chemical Engineering 97 (2017) 76-84.

[31] K. S. Bjorkevoll, A. E. Vollen, I. Barr Aas, S. Hovland, et al., Successful use of real time dynamic flow modelling to control a very challenging managed pressure drilling operation in the north sea, in: SPE/IADC Managed Pressure Drilling and Underbalanced Operations Conference and Exhibition, Society of Petroleum Engineers, 2010.

[32] R. El Boubsi, J. A. Andresen, G. van Og, K. S. Bjørkevoll, R. Nybø, J. O. Brevik, G. Nygaard, G. G. Smith, Demo2000 - drilling mud process control, in: SPE Bergen One Day Seminar, Society of Petroleum Engineers, SPE185929-MS, SPE, 2017. doi:10.2118/185929-MS.

[33] D. S. Pixton, R. A. Shishavan, H. D. Perez, J. D. Hedengren, A. Craig, Addressing ubo and mpd challenges with wired drill pipe telemetry, SPE/IADC Managed Pressure Drilling Underbalanced Operations Conference Exhibition (2014) 16J2: SPE-168953-MS. doi:10.2118/168953-MS.

URL https://doi.org/10.2118/168953-MS

[34] J. B. Rawlings, D. Bonne, J. B. Jorgensen, A. N. Venkat, S. B. Jorgensen, Unreachable setpoints in model predictive control, IEEE Transactions on Automatic Control 53 (9) (2008) 2209-2215. doi:10.1109/TAC.2008.928125.

[35] V. M. Zavala, L. T. Biegler, The advanced-step nmpc controller: Optimality, stability and robustness, Automatica 45 (1) (2009) 86-93, iD: 271426. doi://doi.org/10.1016/j.automatica.2008.06.011.

[36] K. Lu, W. Zhou, G. Zeng, W. Du, Design of PID controller based on a self-adaptive state-space predictive functional control using extremal optimization method (2018). doi://doi.org/10.1016/j.jfranklin.2017.12.034. 
[37] G.-Q. Zeng, J. Chen, L.-M. Li, M.-R. Chen, L. Wu, Y.-X. Dai, C.-W. Zheng, An improved multi-objective population-based extremal optimization algorithm with polynomial mutation, Information Sciences 330 (2016) 49-73.

[38] H. Wang, G. Zeng, Y. Dai, D. Bi, J. Sun, X. Xie, Design of a Fractional Order Frequency PID Controller for an Islanded Microgrid: A Multi-Objective Extremal Optimization Method, Energies 10 (10) (2017) 1502.

[39] M. Aghito, K. S. Bjrkevoll, R. Nyb, A. Eaton, J. Hedengren, Automatic model calibration for drilling automation, 2017, p. 17, j2: SPE-185926-MS. doi:10.2118/185926-MS.

URL https://doi.org/10.2118/185926-MS

[40] J. McLennan, R. S. Carden, D. Curry, C. Stone, R. Wyman, Underbalanced drilling manual, 1997.

[41] O. N. Stamnes, J. Zhou, G.-O. Kaasa, O. M. Aamo, Adaptive observer design for the bottomhole pressure of a managed pressure drilling system, in: 47th IEEE Conference on Decision and Control, CDC 2008, December 9, 2008 - December 11, 2008, 2008.

[42] R. Asgharzadeh Shishavan, C. Hubbell, H. Perez, J. Hedengren, D. Pixton, Combined rate of penetration and pressure regulation for drilling optimization by use of high-speed telemetry, SPE Drilling \& Completion, SPE-170275-PA, 30. doi:10.2118/170275-PA. 